\title{
New Technologies and Automakers Have the Potential to Eliminate Transportation as a Major Factor Contributing to Health Disparities, and Provide Additional Benefits
}

\author{
Kanzoni N. Asabigi \\ Detroit Health and Wellness Promotion, Detroit, Michigan, USA \\ Email: Asabigik@detroitmi.gov
}

How to cite this paper: Asabigi, K.N. (2016) New Technologies and Automakers Have the Potential to Eliminate Transportation as a Major Factor Contributing to Health Disparities, and Provide Additional Benefits. Journal of Transportation Technologies, 6 , 449-456.

http://dx.doi.org/10.4236/itts.2016.65036

Received: June 30, 2016

Accepted: October 28, 2016

Published: October 31, 2016

Copyright $\odot 2016$ by author and Scientific Research Publishing Inc. This work is licensed under the Creative Commons Attribution International License (CC BY 4.0). http://creativecommons.org/licenses/by/4.0/

\begin{abstract}
Transportation as a major barrier to obtaining health care is well documented in literature. It is a major contributing factor to health disparities in urban and rural areas in the United States. A lack of transportation to and from a doctor's office or other ancillary health care services worsened the medical conditions of individuals over time. The cost to society by inefficient use and distribution of health resources to promote the general wellbeing of communities is enormous. New technologies in the automobile industry have the potential to eliminate transportation as a barrier to receiving health care services regardless of a person's socioeconomic status. Automotive technologies including autonomous, driverless and semiautonomous vehicles have the potential to improve how patients get to the doctor to receive health care services more efficiently and timely. However, government, especially public health, must play a critical role at this stage of these new technologies by being at the table to provide guidance on how the new technologies should benefit population and community health.
\end{abstract}

\section{Keywords}

Disparity, Health, Autonomous Vehicles, Transportation

\section{Introduction}

The U.S. Department of Health \& Human Services defines a health disparity as a particular type of health difference that is closely linked with social, economic, and/or environmental disadvantage. Health disparities adversely affect groups of people who 
have systematically experienced greater threats to health based on their racial or ethnic group; religion; socioeconomic status; gender; age; mental health; cognitive, sensory, or physical disability; sexual orientation or gender identity; geographic location; or other characteristics historically linked to discrimination or exclusion [1].

Health disparities significantly affect urban dwellers, minority communities, and the poor, who have little access to transportation services. A lack of access to health care services contributes disproportionately to poor health outcomes for urban and rural dwellers, and transportation is a major barrier for members of these communities in accessing health services. Health disparities claim approximately 83,000 lives annually [2]. Everyone pays for the cost of health disparities either directly or indirectly, including businesses and governments [3].

\section{Transportation as a Major Factor}

Nearly a third of the U.S. population lacks reliable and regular means of transportation [4]. Transportation has long been known as a major factor contributing to health disparities, especially in urban areas, where many of our country's poor and minorities live. Transportation barriers contribute to missed health care appointments, rescheduling of doctor visits, deferred or postponed prescription drug use, and-more important-delayed care [5]. Such delays in accessing health care services often result in slowly worsening chronic diseases that, without warning, may suddenly require acute medical care, leading to a disproportionate use of hospital Emergency Departments by poor and minority populations. The lack of affordable transportation options is often cited as a contributing factor in the exacerbation of health [6].

\section{Transportation Barriers}

Getting to doctors' offices and other ancillary health services providers has been a major barrier to people receiving adequate and appropriate medical services, particularly in urban settings. City buses and subway systems are not the best means of transportation for patients to travel from their homes to the physician's office and back. For example, in some cities the buses are not reliable, as they often do not run according to schedule. This results in long waiting periods and makes it difficult to plan a trip. Also, in some cities, travel time to and from the doctor's office by bus takes over one hour. These public transportation systems most often require a transfer from one bus or subway to another, sometimes two or three times before people reach their destination. Transfers add to travel time and increase the likelihood of missing a connection. In blighted urban areas, people waiting for transportation at bus stops become targets for violence, theft, and sexual harassment or assault. Furthermore, when buses run late, they cause patients to be late to the doctor's office. These patients may not be seen by the doctor, and have to reschedule their appointments. Medical conditions, especially preventable diseases, thus do not get taken care of, leading to worsening conditions that eventually end up being tended to in the emergency room, costing the individual and society more to treat. 
Traveling with children and the elderly can be particularly difficult. Young children and older adults generally move more slowly than the average able-bodied person, so anyone accompanying them must allow extra travel time. Handling one or more children on public transportation can be a hassle for any parent, as they require constant attention. And maneuvering a stroller onto a bus or through a subway turnstile is basically impossible. Most buses and subways are also not equipped to accommodate wheelchairs, so elderly people whose mobility is limited by physical disabilities are also limited access to these forms of public transportation.

According to published studies [7], a large number of urban and rural grandmothers age 60 and older are raising their grandchildren due to their children's economic hardships. In the African American community, grandmothers are themselves more likely to be on welfare, have no car, no driver's license or a suspended license, and no driver's insurance, increasing their risk of health problems due to a lack of access to health care [7]. Given the problems described above involving traveling with children and the elderly, one can imagine how difficult it must be for these women to attempt to use public transportation to take their grandchildren to doctors' appointments.

Because of the various issues previously detailed regarding public transportation, urban dwellers often rely on their own vehicles (which most often are not reliable) or on friends or relatives to take them to the doctor and back. However, when friends or relatives take a patient to the doctor, it is often not guaranteed that he or she will be picked up after the appointment and returned home. After all, friends and family members have their own lives to live. In addition, when one or two people have the only reliable vehicle available among a large group of families, it becomes a burden to be constantly asked to drive others to appointments.

Some state and local governments and health insurance companies have tried to eliminate transportation barriers by offering vouchers for taxis and buses or by paying for other travel alternatives (nonprofit vans, etc.) to provide transportation directly to patients. These efforts do not appear to have been entirely successful and have met with some obstacles. For example, some taxi drivers have refused to pick up patients in certain neighborhoods because of a perceived or actual threat of violence. Taxi drivers in some neighborhoods have been attacked in robbery or attempted robbery situations. Insurance companies, especially Medicaid HMOs, have contracted with taxi companies to transport patients to health service providers and back home. However, access to health care services will continue to be a problem if the threat of violence against taxi drivers makes them feel unsafe picking up patients in certain neighborhoods.

\section{New Transportation Technologies}

\subsection{Door-to-Door, On-Demand Service: Uber and Lyft}

New technologies, especially Uber and Lyft, have the potential to revolutionize the way we move about. The door-to-door, on-demand service is ideal for poor people and minorities needing medical care who do not have any other means of transportation. It is also very convenient for Uber and Lyft drivers to pick up patients from their homes or 
apartments at a specified time to attend a scheduled appointment with a health care provider, and to pick them up after the appointment and take them home.

\subsection{Autonomous Vehicles (AVs): The Benefits of Driverless Cars}

Autonomous vehicles (AVs) are gaining the attention of automobile manufacturers such as Ford and General Motors. In fact, General Motors is in the process of transforming itself into a "mobility company". Individuals with disabilities would benefit tremendously from this new technology, regardless of the severity of their disability. Special vehicles can be designed specifically to move people with wheelchairs and mental health disorders. Vehicles can be created to interact with people with mental health disorders, for example, on route to a doctor's or provider's office and relay critical information to the office prior to the patient's arrival.

Senior citizens, a growing portion of the U.S. population, are living longer and driving late into their eighties, placing themselves and others at high risk of involvement in accidents that result in significant injury or death. Seniors have vision and hearing issues that come with aging; autonomous vehicles could compensate for such problems while providing mobility and independence. The growing number of Americans over 65 with medical problems will no longer need to obtain a driver's license. These new technologies will be able to move them safely and quickly to and from any place they wish to visit.

Other automobile companies are rethinking transportation possibilities. For example, Google's driverless car will be a reality in the future. Apple, Inc. is also rumored to be investing in this technology. Driverless cars would significantly reduce dangerous situations. For example, tickets for DUIs (Driving Under the Influence) would be obsolete, as alcoholics and drug users would be transported home safely with rented mobile (driverless) cars or driven to the nearest hospital if there is a probability the passenger will suffer a life-threatening event such as "alcohol withdrawal". Road rage and other stressful situations that arise during driving would also be significantly reduced as machine-to-machine (M2M) advances improve how vehicles communicate with each other and algorithms are developed to efficiently move vehicles to reduce road congestion and accidents.

\subsection{Reduction of Automobile Accidents}

Another public health benefit will be the reduction of automobile accidents and their accompanying loss of life. Every year in the U.S. about 33,804 people (10.7 per 100,000) die in automobile accidents [8] and thousands of others suffer varying degrees of disability. According to the Altarum Institute [9] over 90\% of the almost 2 million motor vehicle injuries are caused by human error. Machine-to-machine (M2M) communications have the potential to eliminate automobile accidents and thus bring these numbers to almost zero. Pedestrian deaths and injuries caused by automobiles should also be eliminated as a result of advances in automobile technology. However, government needs to lead in setting the agenda and guidelines to protect human lives, because pub- 
lic health is a government function. The Obama administration recently requested $\$ 4$ billion from Congress to help the automotive industry in building these autonomous, driverless or self-driving cars [10]. This huge investment on behalf of taxpayers must be accompanied by embedding the needs of public health and public safety in the development of these new technologies.

\subsection{Parking Alternatives}

Parking in urban areas is a huge waste of land use in U.S. cities. According to the Altarum Institute, in some cities parking takes up a whopping one-third of all land areas, usually occupying prime locations. Autonomous cars are more likely in the future to be used by more than one person. In effect, they would be used more frequently and be on the route transporting people rather than being parked at one location. Therefore, some space that is now used for parking lots can be used to build affordable housing for low-income families. Or, the space can be used to build factories or businesses that can hire urban dwellers, thus reducing the high rates of unemployment, which is a known cause of health disparities because the unemployed are not covered by health insurance and don't have money for daily amenities. The lack of these amenities exacerbates the decline in their health status.

\subsection{Other Benefits of the New Transportation Technologies}

The new transportation technologies provide an opportunity for public health leadership be input into the design of these vehicles to help eliminate health disparities. Governments, especially the federal government, can play an important role in developing policies that protect patients and transportation companies as well. These technologies also offer and expand opportunities for companies like Uber, Lyft, and General Motors to contribute to the wellbeing of communities as well as generating revenues to sustain their businesses. Another collateral benefit is employment. Poor people can get to job interviews as well as their workplace with the use of these vehicles instead of relying on currently available public transportation (which is inadequate in many areas).

Speeding will be a thing of the past, as these autonomous vehicles will be fitted with sensors that can detect the speed limits on highways and in residential areas and adjust the speed of the vehicles accordingly. According to the National Highway Traffic and Safety Administration, 4175 pedestrians died in 2013 in the United States, a growing trend in this segment of road users [11]. The technology already exists to detect objects, including people (especially children) that may be behind a car or vehicle when it is backing up. Fatalities such as that of Alayjah Miller, whose mother didn't see her and accidentally backed over her, would be eliminated, as these vehicles can automatically stop when sensors detect an object in the vehicle's [12]. According to the Insurance Institute for Highway Safety, NHTSA has already promulgated rules requiring all new passenger vehicles to have rear cameras to prevent the estimated 267 people killed and approximately 15,000 individuals injured because of back-overs [13]. Autonomous cars with M2M technology should cut these deaths to zero. These vehicles can also be syn- 
ced with traffic lights, making running through red lights another thing of the past. Road rage would also disappear, as these machines will operate on algorithms rather than on emotions, as human beings do. According to Google, the accidents involving its driverless cars with other vehicles driven by human beings are the result of human error on the part of human drivers rather than the Google cars. With these new technologies, crashes involving driving the wrong way on highways or on one-way streets mostly in urban areas will potentially be eliminated altogether in the near future.

Another advantage of autonomous vehicles or driverless cars would be the reduction of carjacking. Carjacking occurs predominantly in urban areas, resulting in death or physical and psychological injuries. Autonomous vehicles will be difficult to steal, as they can lead law enforcement directly to their location. The vehicles can be fitted with various sensors and cameras to detect and relay to law enforcement any individual in the car or in its vicinity who poses a danger to other people.

General Motors could develop an Uber-like or Enterprise-like "healthcare fleet" that constantly moves people from their homes to the doctor's office, then back to home, work, or school (or other destinations). The federal government, with its enormous purchasing power for healthcare/medical benefits, can negotiate favorable terms and at the same time develop federal rules or guidelines that would be uniform and adopted by all states. Medicaid and Medicare cost containments should thus see significant cost savings with this new transportation technology in the future.

Public health agencies and organizations at all levels of government will have access to sophisticated movement data about people and communities and their health (provided strict PHI rules are enforced). Aggregate data from this new transportation information can provide useful tools for disease surveillance, primary prevention, and intervention.

Electric cars and driverless cars can go almost anywhere in an urban setting. Dangerous places become less important because no human drivers would be involved. There would be no bias and/or stigma exhibited by driverless cars when picking up patients. Tesla's innovative electric cars would be ideal to move in and out of dangerous neighborhoods without the need to refuel. In addition, the cars will lead to significant smog reductions in inner cities, with a resulting impact (yet to be estimated) on diseases like asthma. This is a win for public health as well as a win for the environment.

\section{Conclusions}

The advent of these new technologies is a sign that we should start thinking about public transportation as an historical artifact, especially in urban settings. I cannot predict how long it will be before buses, for example, will disappear, replaced by some other alternatives, but this is inevitable in the not-too-distant future. General Motors has invested $\$ 500$ million in Lyft to develop a system of driverless [14]. GM leadership has shown a forward-thinking attitude regarding the future of transportation when it comes to the profitability and viability of the company, but has not necessarily considered how autonomous vehicles will alter as well as benefit the public health sector. 
I can foresee people in the future renting cars or vehicles as their choice to move from one location to another. GM's concept has the potential to eliminate the differences in mobility between affluent communities and poor ones. Someone can "uber" a Ford Focus, a Lincoln, or a Cadillac depending on his or her taste and ability to pay. As I have discussed in this article, currently existing human-operated car services such as Uber and Lyft as well as the driverless cars that are under development can both improve access to healthcare in the United States. Transportation barriers that formerly hindered the poor and minorities from getting to doctors' appointments-even something as simple as a subway station directional sign that cannot be deciphered by a nonEnglish speaking immigrant-will no longer be a problem.

The use of on-demand transportation and door-to-door services would reduce physical activity for people in urban areas whose only means of exercise is catching a bus or using the subway. Educational programs are needed to illustrate other exercise options for this population. Numerous legal hurdles must also be overcome before autonomous vehicular use is widespread. For example, the issue of liability for these vehicles is major [15]. However, I am confident that such difficulties will be resolved, and I believe that the advantages to public health far outweigh any disadvantages that these new means of transportation present.

\section{Compliance with Ethical Standards}

This article does not contain any studies with animals.

\section{Disclosure of Conflict of Interest}

The author Kanzoni N. Asabigi declares that I have no conflict of interest.

\section{Funding}

The article was not funded by any organization or grant.

\section{References}

[1] Healthy People 2020 (2015) Disparities. U.S. Department of Health \& Human Services. http://healthypeople.gov/2020/about/foundation-health-measures/Disparities

[2] Satcher, D., et al. (2005) What If We Were Equal? A Comparison of the Black-White Mortality Gap in 1960 and 2000. Health Affairs, 24, 459-464. http://dx.doi.org/10.1377/hlthaff.24.2.459

[3] Suthers, K. (2008) Evaluating the Economic Causes and Consequences of Racial and Ethnic Health Disparities. http://www.apha.org/ /media/files/pdf/factsheets/corrected_econ_disparities_final2.ashx

[4] American Public Health Association (APHA) (2009) At the Intersection of Public Health and Transportation. http://www.apha.org/ /media/files/pdf/topics/transport/at_the_intersection.ashx

[5] Syed, S.T., et al. (2013) Traveling towards Disease: Transportation Barriers to Health Care Access. Journal of Community Health, 38, 976-993. http://dx.doi.org/10.1007/s10900-013-9681-1

[6] Surgeon General (2014) Elimination of Health Disparities. U.S. Department of Health \& 
Human Services.

http://www.surgeongeneral.gov/priorities/prevention/strategy/elimination-of-health-dispar ities.html

[7] Whitley, D.M., et al. (2001) Grandmothers Raising Grandchildren: Are They at Increased Risk of Health Problems? Health \& Social Work, 26, 105-114.

http://dx.doi.org/10.1093/hsw/26.2.105

[8] Centers for Disease Control and Prevention (CDC) (2015) FastStats. Accidents or Unintentional Injuries. U.S. Department of Health \& Human Services.

http://www.cdc.gov/nchs/fastats/accidental-injury.htm

[9] Altarum Institute (2015) Autonomous Vehicles and Public Health.

http://altarum.org/our-work/autonomous-vehicles-and-public-health

[10] Spector, M. and Ramsey, M. (2016) U.S. Proposes Spending \$4 Billion to Encourage Driverless Cars. The Wall Street Journal.

[11] National Highway and Traffic Administration (NHTSA) (2016) Everyone Is a Pedestrian. http://www.nhtsa.gov/Pedestrians

[12] Bethencourt, D. and Allen, R. (2015) Oak Park Mother Backs over 1-Year-Old, Killing Her. http://www.freep.com/story/news/local/michigan/oakland/2015/12/24/oak-park-child-runover/77882062/

[13] Insurance Institute for Highway Safety (IIHS) (2014) Rearview Camera Rule Aims to Reduce Backover Crashes. http://www.iihs.org/iihs/sr/statusreport/article/49/4/4

[14] MacMillan, D. (2016) GM Invests \$500 Million in Lyft, Plans System for Self-Driving Cars. The Wall Street Journal.

[15] RAND Corporation (2016) Legal Accelerators and Brakes for Development of Automated Vehicles. http://www.rand.org/pubs/external_publications/EP50602.html

\section{Submit or recommend next manuscript to SCIRP and we will provide best service for you:}

Accepting pre-submission inquiries through Email, Facebook, LinkedIn, Twitter, etc.

A wide selection of journals (inclusive of 9 subjects, more than 200 journals)

Providing 24-hour high-quality service

User-friendly online submission system

Fair and swift peer-review system

Efficient typesetting and proofreading procedure

Display of the result of downloads and visits, as well as the number of cited articles

Maximum dissemination of your research work

Submit your manuscript at: http://papersubmission.scirp.org/

Or contact jtts@scirp.org 